\title{
Turismo Rural na Agricultura Familiar (TRAF): estudo de caso no Circuito de Turismo Sabiá, Matelândia/PR
}

\author{
Graciela Caroline Gregolin ${ }^{1}$ \\ Caroline Monique Tietz Soares ${ }^{2}$ \\ Cristiano Luiz Metzner ${ }^{3}$ \\ Larice Vazata Becker ${ }^{4}$ \\ Elio Jacob Henrich Júnior ${ }^{5}$ \\ Giovana Riva Maggi ${ }^{6}$ \\ Wilson João Zonin ${ }^{7}$
}

\section{Resumo}

Os proprietários rurais estão sendo encorajados, cada dia mais, a buscar fontes alternativas de renda, visando viabilizar sua permanência no campo. Por meio do turismo rural na agricultura familiar, é possível utilizar ativos econômicos que até então não produziam nenhum efeito financeiro direto, conciliando-os com as atividades já desenvolvidas na propriedade. O objetivo deste trabalho foi compreender o desenvolvimento da atividade do turismo rural na agricultura familiar na comunidade Circuito Sabiá, localizada no município de Matelândia, na região oeste do Paraná. A pesquisa caracterizou-se como um estudo de caso de caráter quali-quantitativo e foi desenvolvida em três etapas. A primeira consistiu na visita e observação do local em estudo; a segunda caracterizou-se por entrevista aos proprietários; e, a terceira etapa foi a aplicação de um questionário semiestruturado aos turistas que já visitaram o circuito, e, por fim, a tabulação e análise dos dados. O turismo rural, no Circuito Sabiá, é uma boa alternativa para manter as famílias no campo; contudo, ainda é necessário um maior planejamento e organização, visando ressaltar as potencialidades e minimizar as fragilidades do local.

Palavras-chave: Desenvolvimento rural. Campo. Potencialidades.

1 Mestranda do Programa de Pós-Graduação em Desenvolvimento Rural Sustentável. Universidade Estadual do Oeste do Paraná.gracigregolin@hotmail.com

2 Mestranda do Programa de Pós-Graduação em Desenvolvimento Rural Sustentável. Universidade Estadual do Oeste do Paraná. carol.tietz@hotmail.com

3 Mestrando do Programa de Pós-Graduação em Desenvolvimento Rural Sustentável. Universidade Estadual do Oeste do Paraná. suko_cm@hotmail.com

4 Mestranda do Programa de Pós-Graduação em Desenvolvimento Rural Sustentável. Universidade Estadual do Oeste do Paraná. laricevazata@gmail.com

5 Mestrando do Programa de Pós-Graduação em Desenvolvimento Rural Sustentável. Universidade Estadual do Oeste do Paraná. elio_jacob@hotmail.com

6 Mestranda do Programa de Pós-Graduação em Desenvolvimento Rural Sustentável. Universidade Estadual do Oeste do Paraná. giovana_riva21@hotmail.com

7 Professor Doutor da Universidade Estadual do Oeste do Paraná. wzonin@yahoo.com.br 


\begin{abstract}
Landowners are being increasingly encouraged to seek alternative sources of income, in order to grant their stay in the field. Through the Rural Tourism in Family Farming, it is possible to use economic assets which had not any direct financial profit before, combining them with the activities already carried out on the property. The aim of this study was to understand the development of the Rural Tourism in Family Farming activity in the Sabia's Community, located in the Matelândia's county, in the western region of Paraná. The research was characterized as a qualitative-quantitative case study that was developed in three stages. The first stage was the visit and observation of the site under study, the second wasthe interview of the owners and the third step was the application of a semi-structured questionnaire to the tourists who have visited the circuit and finally, the data were tabulated and analyzed. Rural tourism in Sabia Circuit is a good alternative to keep families in the countryside, however, greater planning and organization, aiming to highlight the strengths and minimize the weaknesses of the site is still necessary.
\end{abstract}

Keywords: Rural development. Coutryside. Potential.

\title{
1 Introdução
}

No século XX, o Brasil ficou internacionalmente conhecido como um país exportador de produtos agropecuários, decorrência do fato de sua economia estar baseada no setor primário. Nesse cenário, ficou evidente o domínio de grandes corporações e latifúndios proprietários de terras e da geração de produtos, principalmente para a exportação. Em vista disso, grande parte do abastecimento do mercado interno realizou-se pelo pequeno produtor rural, que se diferenciava do grupo dominante por utilizar mão de obra familiar para a produção de alimentos, caracterizando-se, assim, como um sistema de agricultura familiar (SILVA, 2010).

Na década de 1980, devido à grande expansão das inovações tecnológicas que se sucederam na produção alimentícia, estes produtores menores e com recursos financeiros limitados, para a ampliação de sua capacidade produtiva e maiores investimentos, perderam espaço no mercado interno, em virtude dos grandes latifúndios, os quais, com investimentos diversificados, conseguiram aumentar a produção, bem como diminuir o valor final do produto (SILVA, 2010; WHITACKER, 2012).

No entanto, um importante fato na história do rural brasileiro foi o reconhecimento oficial da agricultura familiar; desde então, o agricultor familiar não é mais visto apenas como o marginalizado do campo ou o produtor pobre e de baixa renda, mas sim como parte integrante da sociedade, voltando a assumir seu papel na agricultura do país (WANDERLEY, 2000).

A partir dessa situação, houve um estímulo ao desenvolvimento de atividades paralelas à agricultura nestas propriedades rurais, a fim de valorizar a ruralidade, ampliar os recursos e resultados obtidos e, consequentemente, proporcionar inclusão 
social. Dentre estas iniciativas, destaca-se a atividade turística realizada no espaço rural, o Turismo Rural - TR (BRASIL, 2003).

A ruralidade, entendida, de modo geral, como a aproximação do espaço rural e do espaço urbano, como, por exemplo, na prática do turismo rural, traduz-se por "[...] um processo dinâmico de constante reestruturação dos elementos da cultura local com base na incorporação de novos valores, hábitos e técnicas" (CARNEIRO, 1998, p. 61). Desse modo, percebe-se que esta dinâmica entre as populações e culturas pode fortalecer os vínculos locais e as relações sociais (CARNEIRO, 1998).

Com o avanço das políticas públicas para a agricultura familiar, especialmente a partir da criação do Programa Nacional de Fortalecimento da Agricultura Familiar - PRONAF, na década de 90, oportunizou-se a construção do conceito e da prática do Turismo Rural na Agricultura Familiar - TRAF, que, segundo a Lei $n^{\circ} 15.143$, de 31 de maio de 2006, são

todas as atividades turísticas que ocorrem na unidade de produção dos agricultores familiares que mantêm as atividades econômicas típicas da agricultura familiar, dispostos a valorizar, respeitar e compartilhar seu modo de vida, o patrimônio cultural e natural, ofertando produtos e serviços de qualidade e proporcionando bem estar aos envolvidos (PARANÁ, 2006, Art. 01).

Diante dessas considerações, o objetivo deste trabalho foi compreender o desenvolvimento da atividade do TRAF na Comunidade Circuito Sabiá. Para tanto, foi necessário documentar o histórico da localidade, elucidar a organização do turismo na comunidade, avaliar a adequação da infraestrutura local atual e, ainda, em caráter complementar, avaliar a satisfação dos visitantes do TRAF na comunidade. A partir dos resultados obtidos, foi possível elucidar as potencialidades e fragilidades do local, e também expor sugestões de melhorias para a sua evolução.

\section{Metodologia}

Esta pesquisa caracterizou-se como um estudo caso, de caráter quali-quantitativo. O estudo de caso "[...] permite que os investigadores retenham as características holísticas e significativas dos eventos da vida real" (YIN, 2010, p. 24), enquanto a abordagem qualiquantitativa auxilia a coleta de dados, propiciando uma relação dinâmica entre as dimensões do sujeito pesquisador junto aos sujeitos da pesquisa (ENSSLIN; ENSSLIN; VIANNA, 2007).

O cenário da pesquisa foi o Circuito de Turismo Sabiá (Figura 1), organizado na comunidade do Rio Sabiá, localizada no município de Matelândia, na região oeste do Paraná. 


\section{Figura 1 - Representação gráfica da organização do Circuito Sabiá}

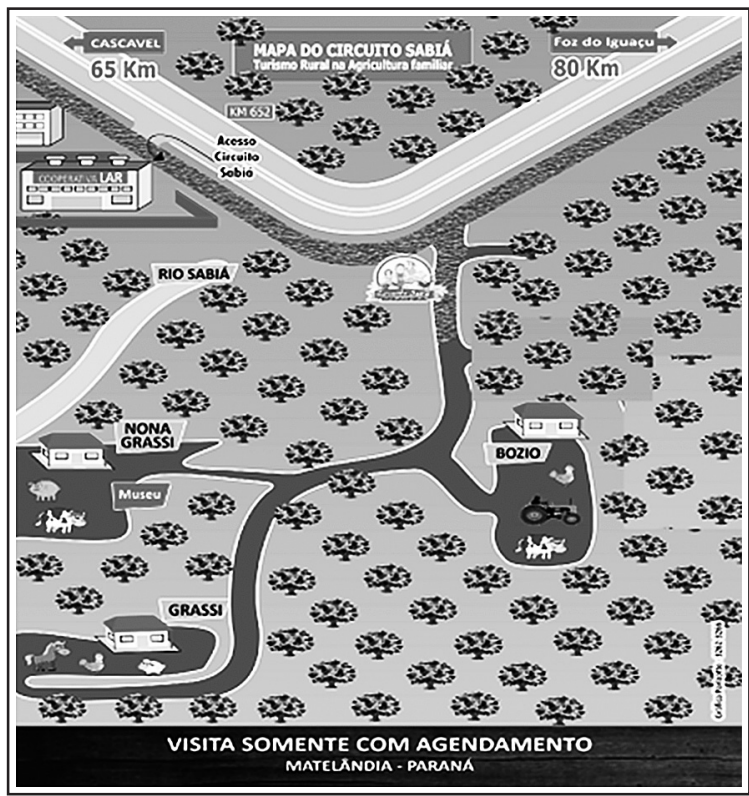

Fonte: Material de divulgação do Circuito Sabiá (2013).

O estudo foi desenvolvido em três etapas: a primeira consistiu na visita e observação do local em estudo, sendo utilizados equipamentos de áudio, vídeo e foto para o registro dos dados. A segunda caracterizou-se por uma entrevista, baseada em um questionário semiestruturado, composto por 25 questões abertas, semiabertas e objetivas, nas três propriedades familiares.

Para padronização e análise dos dados, no decorrer do estudo, as propriedades foram denominadas de acordo com sua oferta turística, sendo 01 - Gastronomia; 02 - Museu e 03 - Pousada. Vale ressaltar que os entrevistados assinaram um Termo de Consentimento Livre e Esclarecido, permitindo a utilização das informações coletadas.

A terceira etapa foi a aplicação de um questionário semiestruturado, composto por onze questões abertas, semiabertas e objetivas, construídas com base na escala de Likert, aos visitantes que já visitaram o Circuito. Nessa etapa, as cinco alternativas da escala foram as seguintes: 1 - Péssimo; 2 - Ruim; 3 - Sem opinião; 4 - Ótimo, e 5 - Excelente. Os questionários foram encaminhados por correio eletrônico, sendo que dos 44 questionários enviados, 59\% foram respondidos, num total de 26 questionários.

A escala de Likert é um instrumento de medição ou coleta de dados empregado em pesquisas quantitativas, especialmente aquelas que expressam opinião (LUNA, 2007), pois "[...] fornece direções sobre a atitude do respondente em relação a cada afirmação" (OLIVEIRA, 2001). De acordo com Allen e Seman (2007), o fator mais importante para a construção da escala é considerar, no mínimo, cinco catego- 
rias de respostas.

A fundamentação teórica do presente estudo foi pautada em trabalhos científicos, incluindo artigos, dissertações e teses nacionais, disponíveis em acervos virtuais, bem como na legislação nacional vigente referente ao tema.

As questões abertas e semiabertas foram analisadas e discutidas de forma dissertativa, ao passo que as questões objetivas foram analisadas e tabuladas por meio de gráficos, utilizando-se um software de planilha eletrônica.

Por fim, a partir dos resultados obtidos, foi construído um panorama da situação atual do Circuito Sabiá, baseando-se na matriz FOFA (Fortalezas, Oportunidades, Fraquezas e Ameaças), a qual, segundo Kummer (2007), é uma ferramenta aplicada para análise de comunidades ou organizações, que possibilita identificar as fortalezas e as fraquezas provenientes do meio interno, e as oportunidades e ameaças que correspondem ao meio externo, ou seja, a forma como o local em estudo se relaciona com o meio no qual está inserido.

\section{Resultados e Discussão}

\subsection{A prática do TRAF na comunidade Circuito Sabiá}

A aceitabilidade das famílias pertencentes ao Circuito Sabiá em relação à pesquisa foi bastante favorável, visto que um representante de cada propriedade (P01, P02 e P03) participou da entrevista respondendo a todas as questões propostas. A faixa etária dos entrevistados ficou entre 40 e 50 anos. No que diz respeito à composição familiar, apenas um deles não possui dependente vivendo na propriedade.

Os resultados obtidos com as três entrevistas realizadas mostraram que a principal fonte de renda dos integrantes do Circuito Sabiá não se concentrava no turismo rural, e sim nas produções de repolho e uva (P01), embutidos (P02) e avicultura e pecuária leiteira (P03). De acordo com Souza (2006), o turismo no espaço rural é uma atividade capaz de integrar-se às atividades produtivas diárias e permite, ainda, a integração e o fortalecimento de novas atividades agropecuárias dentro da propriedade rural.

A P01 foi a pioneira do turismo na comunidade. Com o incentivo de terceiros, iniciou as atividades no ano de 2004; em sequência, no ano de 2007, a P03 ingressou no Circuito, visando à possibilidade de agregar mais renda, e, posteriormente, em meados de 2010, a P02 também se integrou às atividades turísticas na busca da preservação histórica do local. Além disso, o motivo comum que levou as famílias a participarem do TRAF foi a apreciação desta atividade, conforme foi relatado por todos os proprietários.

Os fatos contemplados anteriormente remetem ao resgate histórico-cultural e das tradições locais, passadas de geração a geração, e que atualmente trazem um contraponto à massiva urbanização do campo, bravamente recriando a riqueza sociocultural e socioambiental por meio da agricultura familiar e do turismo rural (MOTTA, 2013).

No que diz respeito ao uso de mão de obra contratada, na P02, havia contra- 
tação na agroindústria, para a produção de embutidos, e, na P03, havia terceirização da limpeza. Portanto são caracterizados como estabelecimentos que praticam agricultura familiar, pois predomina a interação entre trabalho e gestão, na qual os agricultores são os agentes do processo produtivo, enfatizando o trabalho familiar, eventualmente complementado pelo trabalho assalariado (BRASIL, 2006).

Quando questionados sobre planejamento e gestão, os entrevistados responderam que estes são realizados pelas próprias famílias; nesse caso, um representante das três famílias é eleito e fica responsável pela organização por um determinado período. Dentro de uma escala de importância, responderam que a gestão e o planejamento são importantes ou muito importantes para o TRAF no Circuito Sabiá.

Um quesito importante para o desenvolvimento do TRAF é a capacitação dos agricultores, a qual se refere a um processo educativo, relacionado à realidade do meio rural, visando a ampliação e a melhoria nas competências diárias, o que refletirá em melhor produtividade, rentabilidade e competitividade no setor agrícola (SENAR, 2014). Todos os agricultores entrevistados já realizaram algum curso de capacitação, sendo estes oferecidos pelo Serviço Nacional de Aprendizagem Rural SENAR, Prefeitura Municipal, Itaipu Binacional, entre outros.

Outro ponto questionado foi sobre políticas públicas de acesso ao crédito; os entrevistados responderam que, até então, não haviam utilizado linhas de crédito diretamente relacionadas ao TRAF. No entanto, os representantes da P01 e P03 manifestaram interesse nisso, visando à construção de uma cozinha industrial e de uma piscina. Vale salientar que o crédito rural pode gerar grandes oportunidades, investimentos e melhorias nas estruturas das propriedades, aliás, seus benefícios vão muito além, pois traz a modernização do campo e estimula a permanência na agricultura, fortalecendo o processo de sucessão na agricultura familiar (ZIGER, 2014).

Segundo Bonetti e Candiotto (2012), apesar de poucas, existem políticas públicas voltadas ao turismo rural, não obstante a falta de conhecimento sobre elas por parte dos agricultores e, às vezes, pela própria instituição financiadora, que dificulta a sua utilização. De acordo com os participantes da pesquisa, a época do ano em que há maior procura pelo turismo rural é de dezembro a fevereiro, sendo que o maior público é o de famílias. Os mesmos relataram que nos demais meses a procura é reduzida, caracterizando-se por grupo de estudantes e visitantes encaminhados pela Itaipu Binacional.

Dentre os públicos que deixaram marcas significativas, ao visitarem o TRAF na comunidade, os proprietários citaram os estrangeiros e moradores de cidades, por reencontrarem as suas raízes, tradições, costumes e pela oportunidade de estarem próximos à natureza. Foi possível perceber que, apesar de disponibilizar panfletos de divulgação na Prefeitura Municipal de Matelândia, hotéis, restaurantes, feiras e demais estabelecimentos, bem como por meio eletrônico (blogs e redes sociais), a principal forma de divulgação do Circuito Sabiá ainda é o "boca a boca".

Entre os principais resultados que a prática do TRAF trouxe para as famílias, foram citadas a maior organização da propriedade (P01); a expansão do conhecimento (P02); a melhora na questão financeira, a possibilidade de novas amizades e a troca de experiências (P03). A principal motivação das famílias para continuarem 
praticando o TRAF é o gosto pela atividade, que permite, conforme relato do entrevistado da P01, "Conhecer pessoas, conhecer lugares; por meio do TRAF, poder passar seu conhecimento, trocar experiências, entre outros".

\subsection{Avaliação de satisfação dos visitantes}

Verificou-se que $100 \%$ dos respondentes possuíam nível superior completo, e a faixa etária deles ficou entre 23 a 56 anos. Destes, 58\% já tiveram outras experiências com turismo rural, sendo que $80 \%$ delas ocorreram na região Sul do Brasil.

A grande diversidade de profissionais que foram alvo da pesquisa (agrônomos, economistas domésticos, estudantes, biólogos, professores, pedagogos, médicos veterinários, nutricionistas, tecnólogos, entre outros) contribuiu de forma expressiva para a riqueza de dados, tornando os resultados analisados heterogêneos. Sendo assim, pôde-se notar a interdisciplinaridade como uma das principais evidências nos resultados, que, segundo Lima (2003), define uma visão socioambiental além do reducionismo e da visão econômica do TRAF, englobando um panorama holístico, incluindo conceitos relacionados à ecologia, à cultura, à política, espacial e tecnológica.

A primeira análise diz respeito às expectativas dos visitantes em relação ao TRAF no local de estudo, conforme exposto na Figura 2. Nesse aspecto, $61 \%$ dos visitantes declararam que a visita ao Circuito atendeu totalmente às suas expectativas, especialmente pelo contato direto com a natureza e por agregar mais conhecimento sobre a cultura italiana, a gastronomia típica e os desafios da agricultura familiar, conforme os relatos: "Os locais e seus respectivos responsáveis demonstraram seguir parâmetros de qualidade, favorecem a permanência da agricultura familiar, beneficiam o desenvolvimento local e valorizam a cultura" e "Foi muito bom conhecer a realidade daquele lugar, o entusiasmo com que nos receberam, sem falar na beleza natural que pudemos observar e desfrutar".

A sensação de satisfação dos visitantes acontece a cada descoberta de novas paisagens, que são construídas de diferentes maneiras dentro do imaginário do turista, oscilando entre um sentimento superficial, efêmero ou duradouro, provocando diferentes níveis de sensibilização ambiental acerca das propriedades em questão (RENK, 2013). Para aqueles que tiveram suas expectativas pouco ou razoavelmente atendidas, os motivos relatados foram, principalmente, a falta de diversificação das atividades e de estrutura física da P3. 


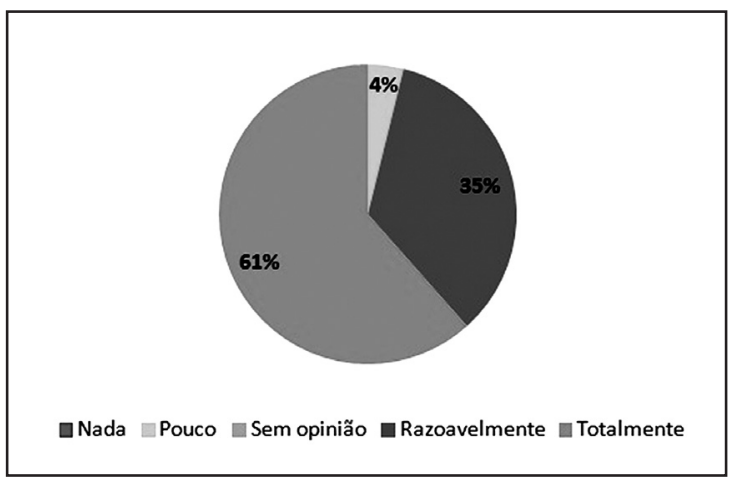

Fonte: Dados da pesquisa (2014).

Quando questionados se o Circuito Sabiá seria um bom atrativo para levar a família, $50 \%$ concordaram totalmente. No entanto, 38\% consideraram o local razoavelmente atrativo, e $8 \%$, pouco atrativo, especialmente devido à falta de opções de atividades de lazer, entre elas, cachoeiras, trilhas, passeios a cavalo e de charretes, pescaria, pequenos animais, bem como a necessidade de melhorias na estrutura da pousada, e 4\% não opinaram. De acordo com as Diretrizes para o Desenvolvimento do Turismo Rural, um dos fatores para a prática do turismo rural é a melhoria da infraestrutura, de transporte e de saneamento, alocando recursos financeiros para a sua execução, além de uma capacitação adequada dos administradores das unidades, para que façam a conexão entre os visitantes e o meio ambiente ali visitado (BRASIL, 2004).

Outro ponto questionado referiu-se ao valor cobrado pelos serviços oferecidos, o qual incluiu três refeições, pernoite e o passeio turístico. Nesse quesito, $65 \%$ dos respondentes concordaram totalmente com o valor cobrado, relatando que o valor foi justo e acessível, conforme relatos dos visitantes: "Valor justo pelo trabalho desenvolvido" e "O valor foi bastante acessivel para hospedagem, três refeições $e$ passeio". Dentre os demais, $23 \%$ concordaram parcialmente, sobretudo pela falta de estrutura em relação à pousada. Entretanto, $8 \%$ declararam que o valor cobrado pouco condiz, pois poderia ser estabelecido um preço maior pelos serviços ofertados, e $4 \%$ preferiram não opinar. Essa análise é muito importante para que o produtor compreenda melhor o seu consumidor, elencando os pontos de melhoria e investimentos necessários, objetivando o equilíbrio entre melhores preços, qualidade para o turista e maior renda para o produtor (BRASIL, 2004).

Observa-se na Figura 3 a avaliação dos visitantes em relação aos quesitos acesso, hospedagem, hospitalidade, restaurante, alimentação, museu, atrativos de lazer, paisagem e preservação ambiental. 
Figura 3 - Avaliação dos visitantes em relação ao acesso (A), hospedagem (B), hospitalidade $(C)$, restaurante (D), alimentação $(E)$, museu (F), atrativos de lazer (G), paisagem (H) e preservação ambiental (I)

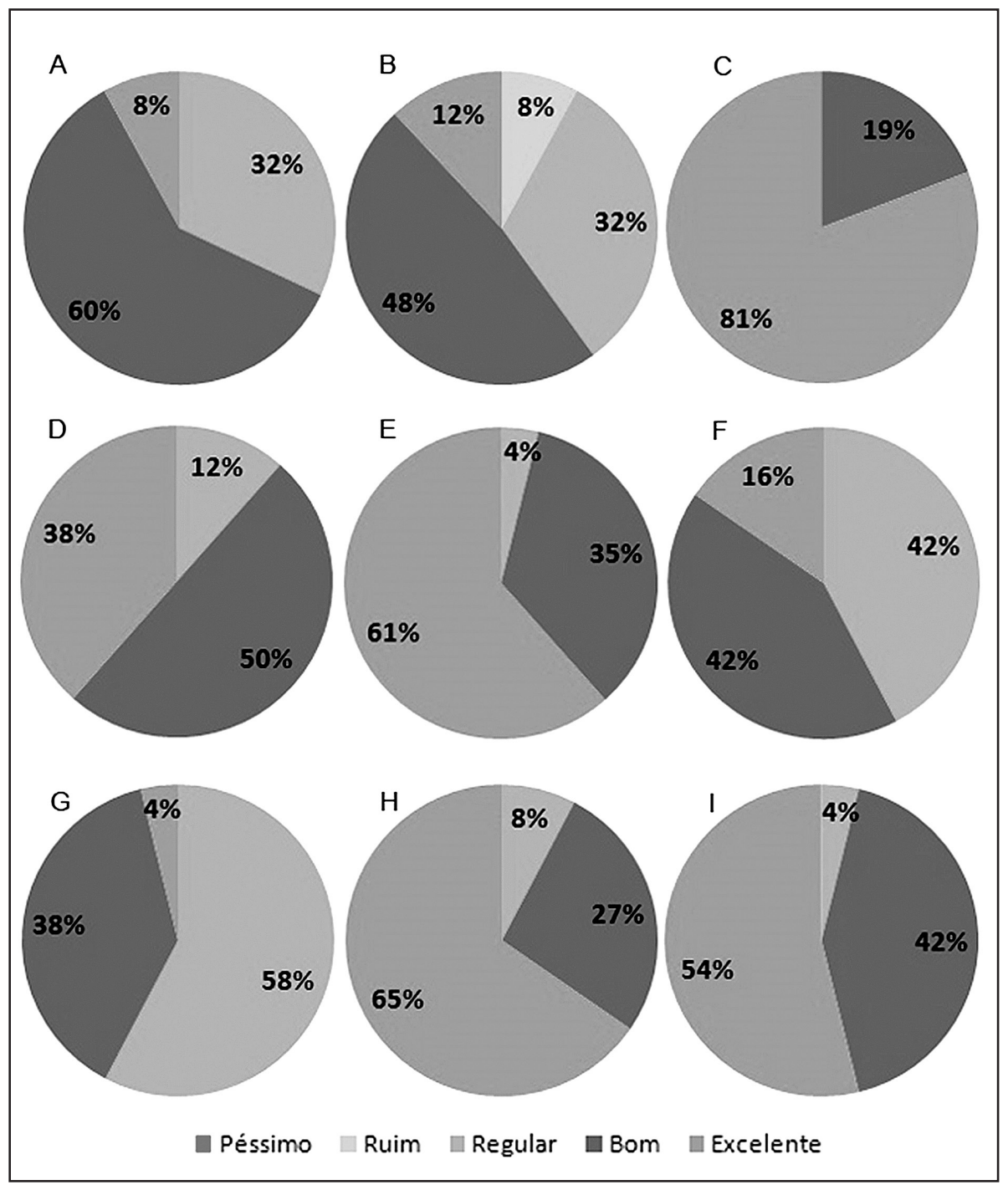

Fonte: Dados da pesquisa (2014).

Averiguou-se que o acesso ao circuito (A), a hospedagem (B), o museu (F) e os atrativos de lazer $(G)$ ficaram, em grande parte das avaliações, entre "regular" e "bom".

A questão de acesso é fundamental na prática do turismo, uma vez que o deslocamento é um fator inerente à existência da prática turística, condicionando muitas vezes o desenvolvimento da atividade na localidade (GOVEIA et al., 2011). No que tange à hospedagem, a deficiência de melhores acomodações apareceu mais uma 
vez como um dos fatores limitantes. No museu (Figura 4), foi mencionada a ausência de identificação nos objetos expostos, sendo esta fundamental para a compreensão do histórico local, bem como a necessidade de inclusão de mais elementos. Entre os atrativos de lazer, a necessidade de mais opções foi novamente levantada.

Figura 4 - Peças do museu na P02

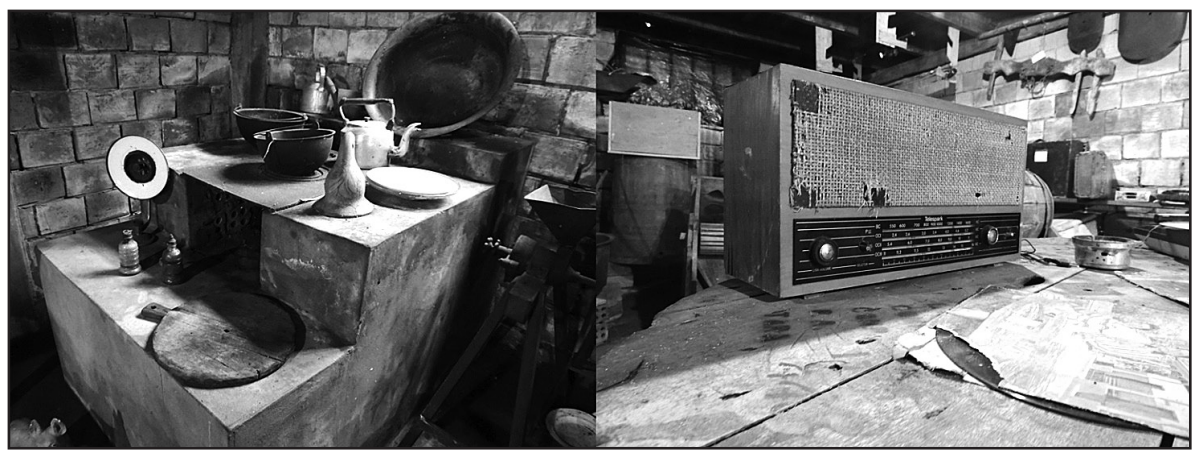

Fonte: Dados da pesquisa (2014).

Restaurante (D), alimentação (E), paisagem (H) e preservação ambiental (I) foram avaliados entre "bom" e "excelente", ao passo que a hospitalidade (C) foi o item mais satisfatório: $81 \%$ dos respondentes a avaliaram como "excelente", e também o mais citado no momento em que se indagou o que mais apreciaram durante a visita ao circuito.

Constatou-se que o local estudado, de acordo com a visão dos visitantes, dispunha de belas paisagens, preservação ambiental (Figura 5), cultura e alimentação típica (Figura 6), o que proporcionou um ambiente agradável.

Ccontudo, para que haja total conforto dos visitantes e, consequentemente, um maior desenvolvimento da prática do turismo rural no local, faz-se necessário minimizar os fatores críticos apontados neste estudo acerca, muitas vezes, da falta de investimentos e de manutenção das propriedades, tanto pelas iniciativas públicas e privadas, quanto pela ausência de regulamentações que fomentem o investimento e o seu crescimento. 
Figura 5 - Paisagens e preservação ambiental na P01 e P03

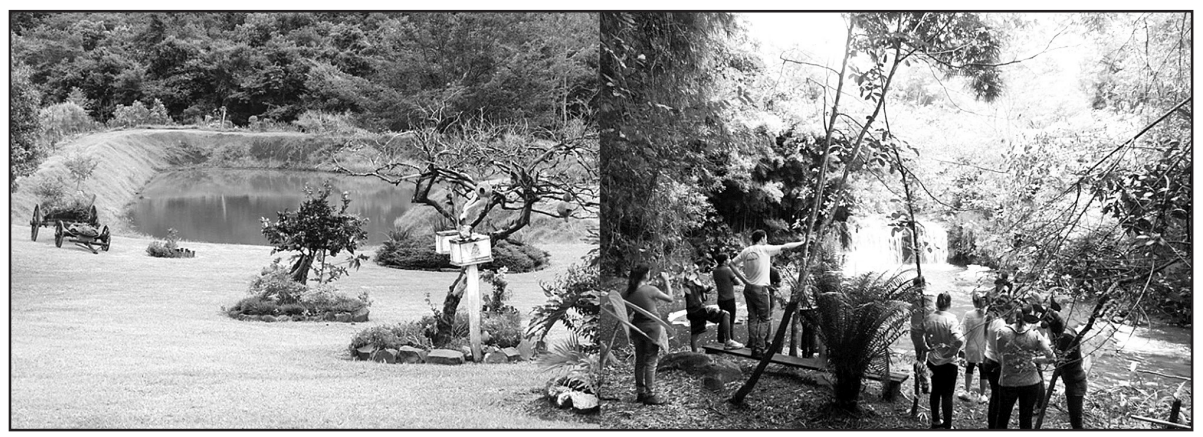

Fonte: Dados da pesquisa (2014).

Figura 6 - Cultura e gastronomia típica na P01

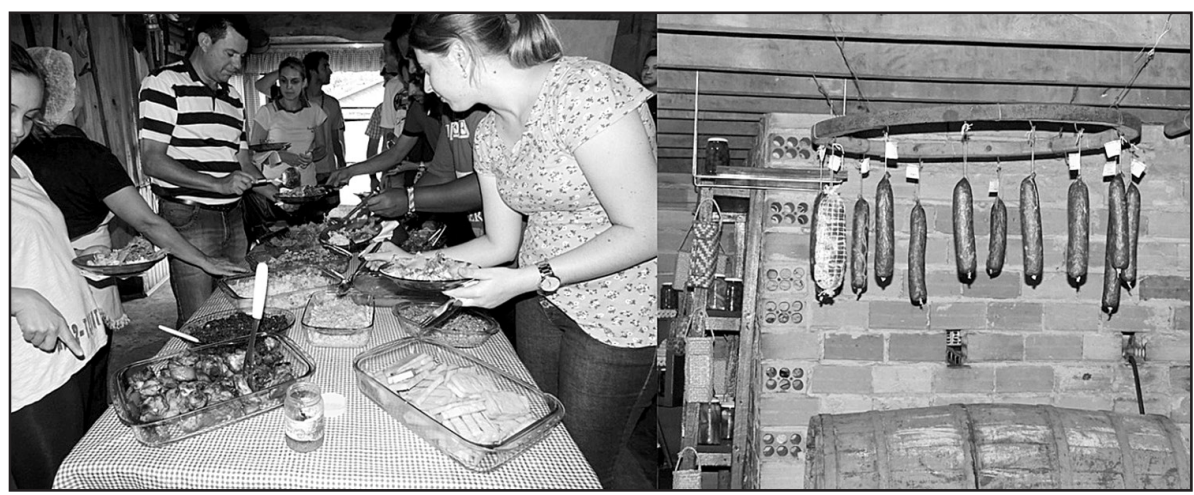

Fonte: Dados da pesquisa (2014).

Por fim, as sugestões manifestadas pelos visitantes que participaram da pesquisa foram estas: passeio ecológico ou trilhas; passeio a cavalo e bicicleta; rapel; luau; mais espaços destinados ao lazer; implantação de mais atrativos para crianças (parque infantil); guia turístico, para acompanhar as atividades; melhorias das condições de hospedagem, incluindo mais banheiros, chuveiros, acomodações (individuais e/ou duplas e/ou triplas) e maior ventilação; capacitação gerencial em atendimento e planejamento; mais atividades culturais; melhorias na estrutura do museu; construção de local específico para a produção das refeições e melhores condições de acesso (calçamento).

É importante salientar, conforme observação da realidade local, que tais meIhorias não são de rápida e fácil implementação, mas é de fundamental importância que esses fatores sejam considerados, mesmo que a longo prazo, para o avanço das atividades que envolvem o Turismo Rural na Agricultura Familiar. 
Diante da análise dos questionários, tanto dos respondidos pelos proprietários como pelos visitantes, foi possível verificar as potencialidades e as fragilidades que interferem na prática do turismo na comunidade (Quadro 1). De acordo com a metodologia da matriz FOFA, o levantamento dos pontos fortes e fracos, em conjunto, possibilita o diagnóstico da situação atual de uma organização, e, a partir disso, a criação de estratégias para traçar as metas que visam alcançar os objetivos e superar as dificuldades (TALANCÓN, 2006).

Segundo Kummer (2007), deve-se aproveitar as fortalezas e apanhar as oportunidades para minimizar as fraquezas e evitar as ameaças.

\section{Quadro 1 - Matriz FODA}

\begin{tabular}{|c|c|}
\hline \multicolumn{2}{|c|}{ AMBIENTE INTERNO } \\
\hline FORTALEZAS & FRAQUEZAS \\
\hline Motivação & Infraestrutura \\
\hline Organização & Atrativos de Lazer \\
\hline Cultura e Tradição & Planejamento \\
\hline Gastronomia & Gestão \\
\hline & Divulgação \\
\hline \multicolumn{2}{|c|}{ AMBIENTE EXTERNO } \\
\hline OPORTUNIDADES & AMEAÇAS \\
\hline Paisagem & Acesso \\
\hline Apoio da Itaipu e Universidades & Falta de Capacitação Específica \\
\hline Políticas Públicas & \\
\hline
\end{tabular}

Fonte: Dados da pesquisa (2014).

A infraestrutura inadequada, a falta de atrativos de lazer, a divulgação (fraquezas) e o acesso inadequado (ameaças) podem ser minimizados pelo acesso a políticas públicas e apoio das instituições (oportunidades). A falta de planejamento e de gestão (fraquezas) são decorrentes da falta de capacitação específica (ameaça), mas também podem ser superadas pelo apoio de instituições (oportunidades). Ademais, destacam-se as fortalezas, as quais são atributos indispensáveis no processo de consolidação da atividade turística das propriedades. Nesse aspecto, observou-se que, no Circuito Sabiá, os quatro pontos de ambos os ambientes estiveram inter-relacionados. 


\section{Conclusão}

O turismo rural no Circuito Sabiá é uma boa alternativa para manter as famílias no campo, pois possibilita uma nova opção para o incremento da renda, tendo em vista que se mantêm as atividades agrícolas diárias, a preservação ambiental, a tradição e a cultura local, ao mesmo tempo em que permite aos visitantes, especialmente os oriundos do meio urbano, o contato com o espaço rural.

De acordo com a opinião dos visitantes, o local em estudo dispõe de diversos fatores positivos que favorecem a prática do turismo, todavia carece especialmente de reparos na infraestrutura.

Evidencia-se que é preciso realizar as melhorias sugeridas pelos visitantes, principalmente no que tange à infraestrutura, contudo é importante lembrar-se das distinções existentes entre TR e TRAF, pois o Turismo Rural na Agricultura Familiar desenvolve-se juntamente com as demais atividades da propriedade, senda elas os reais atrativos da comunidade.

Diante do exposto, percebe-se que o Circuito Sabiá possui potencial para o desenvolvimento do turismo rural familiar, tendo em vista que as famílias participantes já estão motivadas para realizar tal atividade, contudo ainda é necessário um maior planejamento e organização, visando ressaltar as potencialidades e minimizar as fragilidades.

\section{Referências}

ALLEN, I.E.; SEAMAN, C.A. Likert Scales and Data Analyses. 2007. Disponível em: <http://mail.asq.org/quality-progress/2007/07/statistics/likert-scales-and-dataanalyses.html>. Acesso em: 18 maio 2014.

BONETTI, L.A.; CANDIOTTO, L.Z.P. Políticas públicas federais de turismo rural e o turismo rural na agricultura familiar (TRAF). In: XXI Encontro Nacional de Geografia Agrária. Uberlândia, 2012.

BRASIL. Lei $\mathrm{n}^{\circ} 11.326$, de 24 de julho de 2006. Estabelece as diretrizes para a formulação da Política Nacional de Agricultura Familiar e Empreendimentos Familiares Rurais. Brasília: Diário Oficial da União, 2006.

. Ministério do Turismo. Diretrizes para o Desenvolvimento do Turismo Rural no Brasil. Brasília: Ministério do Turismo, 2004.

. SAF/MDA Secretaria de Agricultura Familiar/Ministério Desenvolvimento Agrária. Programa de Turismo Rural na Agricultura Familiar. Brasil, 2003.

CARNEIRO, M.J. Ruralidade: novas identidades em construção. Estudos: Sociedade e Agricultura, n. 11, out. 1998. Disponível em: <http://r1.ufrrj.br/esa/V2/ojs/index. php/esa/article/viewFile/135/131>. Acesso em: 7 jun. 2014. 
ENSSLIN, L.; ENSSLIN, S.R.; VIANNA, W.B. O design na pesquisa quali-quantitativa em engenharia de produção - Questões a considerar. Revista Gestão Industrial. Universidade Tecnológica Federal do Paraná - UTFPR Campus Ponta Grossa - Paraná Brasil. v. 3, n. 3: p. 172-185, 2007.

GOVEIA, E.F.; FERNANDES, D.L.; MAGANHOTTO, R.F. Análise sobre infraestrutura de acesso das propriedades rurais dos jovens vinculados ao CEDEJOR, da região Centro Sul do Paraná. In: VII ENPPEX - Encontro Paranaense de Pesquisa e Extensão em Ciências Sociais Aplicadas e II Seminário dos Cursos de Ciências Sociais Aplicadas da Fecilcam. 2011.

KUMMER, L. Metodologia participativa no meio rural: uma visão interdisciplinar. Conceitos, ferramentas e vivência. Salvador: GTZ, 2007.

LIMA, J.J.S. Turismo sustentável, alternativa de desenvolvimento local e conservação ambiental. Uma análise interdisciplinar do PRODETUR - CE. 2003. 212 f. Dissertação (Mestrado em Desenvolvimento e Meio Ambiente) - Universidade Federal do Ceará, Fortaleza, 2003.

LUNA, S.M.M. Manual práctico para el diseño de la Escala Likert. Xihmai - Revista de Investigación de la Universidad La Salle Pachuca. v. 2. n. 4. 2007. Disponível em: <http://www.lasallep.edu.mx/xihmai/index.php/xihmai/article/view/83/61>. Acesso em: 18 maio 2014.

MOTTA, E.R.G. Turismo no espaço rural: as transformações socioambientais no Caminho do Vinho em São José dos Pinhais/PR. 2013. 133f. Dissertação (Mestrado em Sociologia) - Setor de Ciências Humanas, Letras e Artes da Universidade Federal do Paraná, Curitiba, 2013.

OLIVEIRA, T.M.V. Escalas de mensuração de Atitudes: Thurstone, Osgood, Stapel, Likert, Guttman, Alpert. Revista Administração online. v. 2, n. 2. 2001. Disponível em: <www.fecap.br/adm-online/art22/tânia/htm>. Acesso em: 17 maio 2014.

PARANÁ. Lei n. 15.143, de 31 de maio de 2006. Define as atividades turísticas que especifica, como atividades de "Turismo Rural na Agricultura Familiar". Curitiba: Diário Oficial, 2006.

RENK, V.E. Turismo e cultura: um diálogo interdisciplinar. Caderno de Estudos e Pesquisas do Turismo. Curitiba, v. 2, p. 63-79, jan./dez. 2013.

SENAR. Serviço Nacional de Aprendizagem Rural. Formação Profissional Rural O que é? Disponível em: <http://www.faespsenar.com.br/senar/pagina/exibe/ formacao-profissional-rural/o-que-e/134>. Acesso em: 15 maio 2014.

SILVA, B.E. Turismo Rural e Agricultura Familiar: um estudo sobre a efetividade do Programa Turismo Rural na Agricultura Familiar na comunidade Pedra Redonda, Araponga-MG. 2010. 95 f. Monografia (Bacharel em Turismo) - Universidade Federal de Minas Gerais, Belo Horizonte, 2010. 
SOUZA, L. S. Turismo e desenvolvimento local sustentável na Paraíba.

Campina Grande-Paraíba, 2006. Disponível em: <http://biblioteca.uglobalcusco. edu.pe/material-digital/tur-066.pdf>. Acesso em: 13 maio 2014.

TALANCÓN, H.P. La Matriz FODA: Alternativa de diagnóstico y determinación de estrategias de intervención en diversas organizaciones. Enseñanza e Investigación en Psicologia, v. 12, n. 1: 113-130 jan./jun., 2007.

WANDERLEY, M.N.B. A valorização da agricultura familiar e a reivindicação da ruralidade no Brasil. Desenvolvimento e Meio Ambiente, n. 2, p. 29-37. jul./dez., 2000.

WHITACKER, G.M. (Re)produção do espaço rural a partir da inovação técnica. Considerações sob a perspectiva da ecologia política. Revista Digital para Estudiantes de Geografía y Ciencias Sociales, GeoGraphos. p. 1-30. 2012.

YIN, R.K. Estudo de caso: planejamento e métodos. Porto Alegre: Bookman, 2010.

ZIGER, V. O Crédito Rural e a Agricultura Familiar: desafios, estratégias e perspectivas. 2014. Disponível em: <http://www.cresol.com.br/site/upload/ downloads/183.pdf>. Acesso em: 15 maio 2014. 